University of Nebraska - Lincoln

DigitalCommons@University of Nebraska - Lincoln

6-1-2004

\title{
Magnetic nanotubes produced by hydrogen reduction
}

\author{
Yucheng Sui \\ University of Nebraska-Lincoln, ysui2@unl.edu \\ Ralph Skomski \\ University of Nebraska-Lincoln, rskomski2@unl.edu \\ Kory D. Sorge \\ University of Nebraska-Lincoln, sorge@physics.fau.edu \\ David J. Sellmyer \\ University of Nebraska-Lincoln, dsellmyer@unl.edu
}

Follow this and additional works at: https://digitalcommons.unl.edu/physicssellmyer

Part of the Physics Commons

Sui, Yucheng; Skomski, Ralph; Sorge, Kory D.; and Sellmyer, David J., "Magnetic nanotubes produced by hydrogen reduction" (2004). David Sellmyer Publications. 25.

https://digitalcommons.unl.edu/physicssellmyer/25

This Article is brought to you for free and open access by the Research Papers in Physics and Astronomy at DigitalCommons@University of Nebraska - Lincoln. It has been accepted for inclusion in David Sellmyer Publications by an authorized administrator of DigitalCommons@University of Nebraska - Lincoln. 


\title{
Magnetic nanotubes produced by hydrogen reduction
}

\author{
Y. C. Sui, ${ }^{a)}$ R. Skomski, K. D. Sorge, and D. J. Sellmyer \\ Department of Physics and Astronomy and Center for Materials Research and Analysis, \\ University of Nebraska, Lincoln, Nebraska 68588
}

(Presented on 8 January 2004)

\begin{abstract}
FePt and $\mathrm{Fe}_{3} \mathrm{O}_{4}$ nanotubes are produced by hydrogen reduction in nanochannels of porous alumina templates and investigated by electron microscopy, $\mathrm{x}$-ray diffraction, and superconducting quantum interference device magnetometry. Loading the templates with an Fe chloride and Pt chloride mixture, followed by hydrogen reduction at $560{ }^{\circ} \mathrm{C}$, leads to the formation of ferromagnetic $\mathrm{FePt}$ nanotubes in the alumina pores. An Fe nitrate solution, thermally decomposed at $250{ }^{\circ} \mathrm{C}$ and reduced in hydrogen for $2.5 \mathrm{~h}$ at the same temperature, yields $\mathrm{Fe}_{3} \mathrm{O}_{4}$ tubes. The versatility of the method indicates that materials with a wide range of parameters can be produced. (C) 2004 American
\end{abstract} Institute of Physics. [DOI: 10.1063/1.1688651]

\section{INTRODUCTION}

The search for new geometries is an important aspect of magnetic nanotechnology, and past research has lead to structures such as nanodots, nanowires, and antidots. ${ }^{1-3} \mathrm{An}$ emerging area is the synthesis of tubular nanostructures, which was pioneered in inorganic chemistry. ${ }^{4-7}$ The methods used up to now, such as chemical synthesis ${ }^{1}$ and templatedirected growth, ${ }^{8-10}$ make it difficult to tune the magnetic properties of the structures. This refers, in particular, to magnetic quantities such as anisotropy and coercivity, which are important for many present and future applications in permanent magnetism, magnetic recording, and spin electronics.

Here, we create nanotubes in porous alumina templates by chemical deposition and hydrogen reduction. To demonstrate that template-directed chemical synthesis of these magnetic nanotubes is a highly efficient and versatile approach, we focus on ordered $L 1_{0} \mathrm{FePt}$ and $\mathrm{Fe}_{3} \mathrm{O}_{4}$. We describe the hydrogen processing technique, investigate the produced magnetic nanotubes, and briefly discuss some potential applications.

\section{NANOTUBE FABRICATION}

To form the nanotubes, alumina templates are used to provide an array of pores with a nominal diameter of 200 $\mathrm{nm}$. To remove water and fully transform the aluminum, the substrates are preannealed in air at $600{ }^{\circ} \mathrm{C}$ for $10 \mathrm{~min}$ before use. $^{11}$

To form the ferrimagnetic $\mathrm{Fe}_{3} \mathrm{O}_{4}$ nanotubes, the substrates were wetted with alcohol and loaded with a $65 \mathrm{wt} \%$ $\mathrm{Fe}\left(\mathrm{NO}_{3}\right)_{3} \cdot 9 \mathrm{H}_{2} \mathrm{O}$ in alcohol solution at $25^{\circ} \mathrm{C}$. This solution was then forced into the template pores at the same temperature using a pressure cell. The loaded films were cleaned,

\footnotetext{
a) Author to whom correspondence should be addressed; electronic mail:
} ysui@unlserve.unl.edu mounted on a sample holder, and placed in the oven with pores horizontal. They were first heated in air at a rate of $10^{\circ} \mathrm{C} / \mathrm{min}$ to $250^{\circ} \mathrm{C}$ for decomposition of the iron nitrate. They were then reduced at the same temperature for $2.5 \mathrm{~h}$ in flowing hydrogen and subsequently cooled to room temperature.

To create FePt nanotubes, the templates were similarly prepared and loaded with a mixture of $\mathrm{H}_{2} \mathrm{PtCl}_{6} \cdot 6 \mathrm{H}_{2} \mathrm{O}$ and $\mathrm{FeCl}_{3} \cdot 6 \mathrm{H}_{2} \mathrm{O}$ having an Fe:Pt atomic ratio of 1:1. The loaded templates were then fixed on a sample holder, again with pores mounted horizontally, and placed in an oven with flowing hydrogen for $1.5 \mathrm{~h}$ at $560^{\circ} \mathrm{C}$. After the nanotubes were formed, samples were etched in a $0.3 \mathrm{M} \mathrm{NaOH}$ aqueous solution and the precipitates dispersed in acetone.

\section{STRUCTURAL CHARACTERIZATION}

The FePt tubes were characterized by transmission electron microscopy (TEM) and scanning electron microscopy

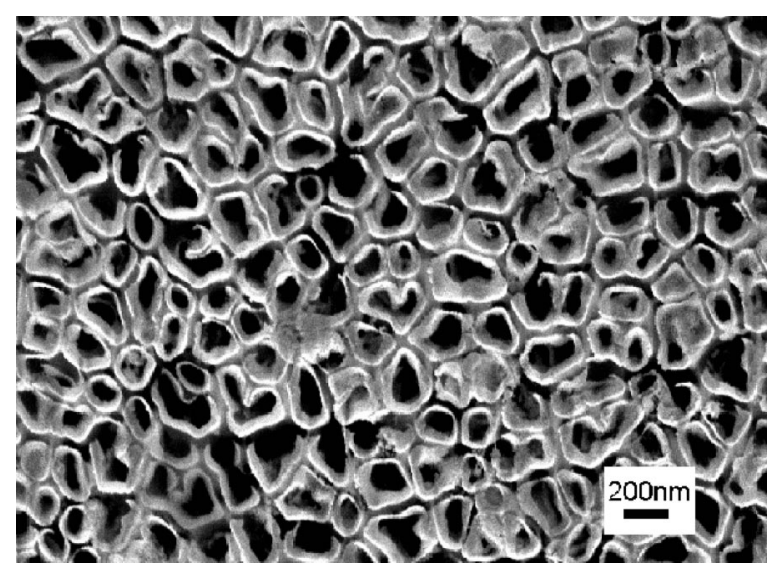

FIG. 1. End view scanning-electron micrograph of an FePt sample etched in $0.3 \mathrm{M} \mathrm{NaOH}$ aqueous solution for $30 \mathrm{~min}$. It shows a closely packed $\mathrm{FePt}$ nanotube array grown in the pores of the template. 


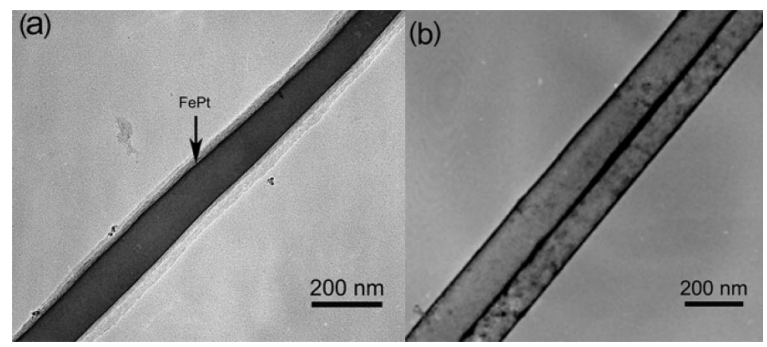

FIG. 2. Transmission-electron micrographs of the magnetic nanotubes: (a) an isolated composite nanotube of FePt surrounded by alumina and (b) two adjacent $\mathrm{Fe}_{3} \mathrm{O}_{4}$ nanotubes released from the matrix.

(SEM). To prepare the sample for morphological characterization, a drop of the suspension of etched precipitates was placed on a TEM copper grid. Figure 1 is a SEM showing the FePt tubes after etching the samples in a $\mathrm{NaOH}$ solution for $30 \mathrm{~min}$. The white deformed donut shapes are FePt, indicating that close-packed nanotubes were formed inside the pores. A likely explanation for the somewhat asymmetrical cross section of the tube ends is that the templates were mounted on a sample holder with pores horizontal. As a consequence, the liquid $\mathrm{Fe}$ and $\mathrm{Pt}$ chloride mixture near the pore openings may tend to flow out of the tubes and accumulate during heating in hydrogen before reduction. A rough calculation based on fractional $\mathrm{Fe}$ and $\mathrm{Pt}$ contents in the initial solution gives a nominal FePt wall thickness of about $10 \mathrm{~nm}$. The apparent wall thickness in this figure is larger than this because of surface tension and/or other end effects.

Figure 2(a) shows a TEM image of the FePt sample taken after etching for $50 \mathrm{~min}$ and dispersing in acetone. The image is a composite tube, an FePt tube encased by alumina. Regarding the driving force for the formation of the $\mathrm{FePt}$ tubes, and considering the laminar growth of $\mathrm{Co}$ on an $\mathrm{Al}_{2} \mathrm{O}_{3}$ substrate ${ }^{12}$ it is reasonable to assume a chemical bond between the interface of the FePt alloy and the inner walls of the nanochannels. Figure 2(b) shows two adjacent $\mathrm{Fe}_{3} \mathrm{O}_{4}$ nanotubes released from the template. In this image, the alumina matrix is removed completely and only the magnetic nanotubes are left.

The thermal stability of the template is crucial to the morphology and magnetic properties of the nanotubes formed by this template-directed chemical reduction technique. The porous alumina templates remain amorphous as long as the heating temperature is $600{ }^{\circ} \mathrm{C}$ or below. When increasing the temperature, the substrates partially crystallize - into $\gamma$ alumina at $700{ }^{\circ} \mathrm{C}$ and subsequently into $\delta$ alumina at even higher temperatures. A volume contraction is expected because of the improved atomic packing in this transition. Secondary pores with an average diameter of around $4 \mathrm{~nm}$ will be created in the walls of the initial pores. ${ }^{13}$

At temperatures above $600^{\circ} \mathrm{C}$ a morphology change is observed in the FePt due to structural evolution of the template. This is demonstrated in Fig. 3 which shows a TEM image of broken pieces of a nanotube after a heat treatment at $900{ }^{\circ} \mathrm{C}$ for $30 \mathrm{~min}$ in hydrogen. FePt nanoparticles ranging in size from 5 to $50 \mathrm{~nm}$ were found on the inner walls of the template. It is interesting to note that some of the particles have an elongated shape along the pore. The particles origi-

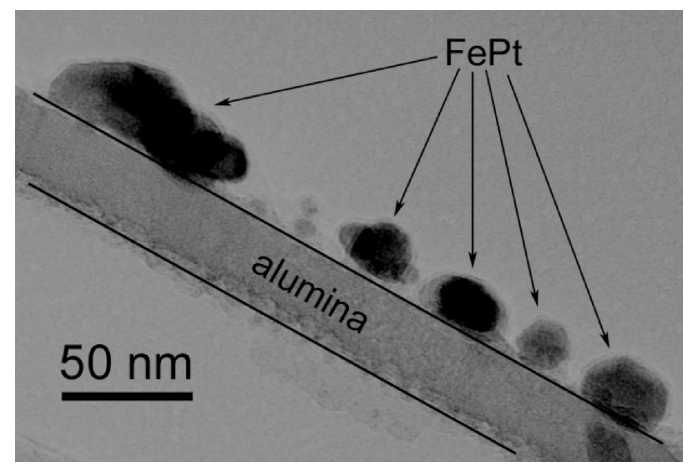

FIG. 3. TEM micrograph of FePt nanoparticles that form when the system is reduced at $900^{\circ} \mathrm{C}$ for $30 \mathrm{~min}$ in hydrogen.

nate from the breaking of the film formed on the inner wall of pores at lower temperature and it is therefore reasonable that some of them should exhibit an elongated shape.

Figure 4 shows x-ray diffraction (XRD) patterns of FePt and $\mathrm{Fe}_{3} \mathrm{O}_{4}$ after hydrogen reduction. The XRD data reveal that the crystal structure of $\mathrm{Fe}_{3} \mathrm{O}_{4}$ is cubic, whereas the $\mathrm{FePt}$ crystallizes in the tetragonal $L 1_{0}$ structure. Both structures agree with what one expects from the corresponding bulk compounds. For the $\mathrm{Fe}_{3} \mathrm{O}_{4}$ nanotubes, we see that composition is also dependent upon the reduction time. By allowing the system to remain at $250{ }^{\circ} \mathrm{C}$ for $4 \mathrm{~h}$ rather than $2.5 \mathrm{~h}$, a peak related to $\alpha \mathrm{Fe}$ begins to form. With respect to the linewidths, the patterns are reminiscent of those of typical nanowires deposited in alumina, ${ }^{8}$ indicating that the tubes are polycrystalline with crystallite sizes of a few nanometers.

\section{MAGNETIC PROPERTIES}

Figure 5 shows hysteresis loops of $\mathrm{FePt}$ (a) and $\mathrm{Fe}_{3} \mathrm{O}_{4}$ (b), measured by superconducting quantum interference device (SQUID) magnetometry along the tube axes. One striking difference in these data is that the FePt nanotubes have a considerably higher coercivity; about $26.5 \mathrm{kOe}$ at $5 \mathrm{~K}$. As

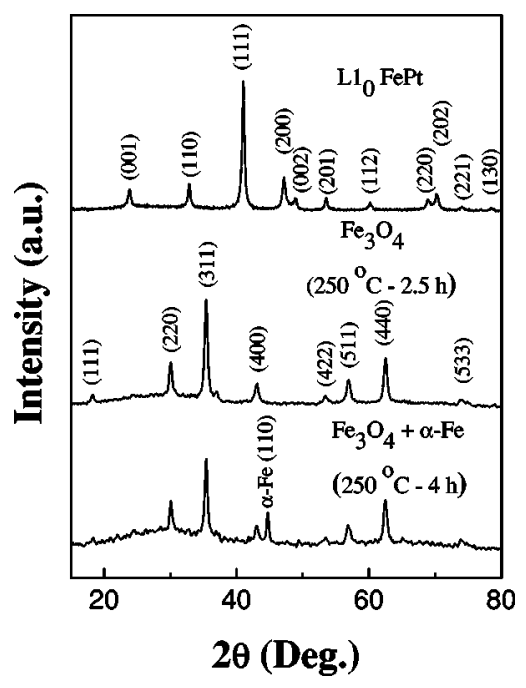

FIG. 4. X-ray diffraction patterns of $\mathrm{FePt}$ reduced at $560{ }^{\circ} \mathrm{C}$ and $\mathrm{Fe}_{3} \mathrm{O}_{4}$ reduced at $250{ }^{\circ} \mathrm{C}$ for 2.5 and $4 \mathrm{~h}$, respectively. Note the $\alpha$-Fe peak that appears with longer reducing time in the $\mathrm{Fe}_{3} \mathrm{O}_{4}$ system. 


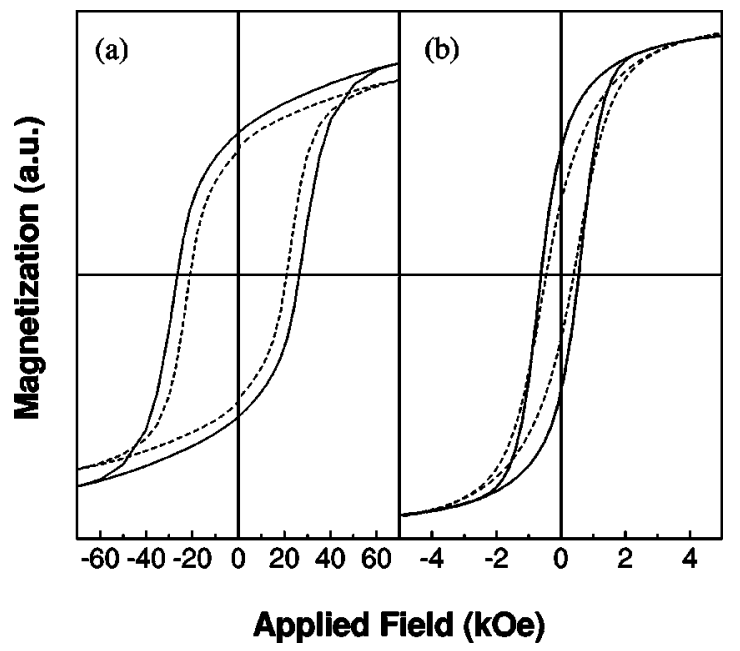

FIG. 5. Hysteresis loops for $\mathrm{FePt}$ (a) and $\mathrm{Fe}_{3} \mathrm{O}_{4}$ (b). The external field is parallel to the tubes in each case. In (a), data at $5 \mathrm{~K}$ (solid curve) and $300 \mathrm{~K}$ (dashed curve) are shown. In (b), data for $\mathrm{Fe}_{3} \mathrm{O}_{4}$ tubes reduced for $2.5 \mathrm{~h}$ (solid curve) and $4 \mathrm{~h}$ (dashed curve) are shown.

expected, the saturation magnetization, the remanent magnetization, and coercivity all fall as the system is heated to room temperature. When the FePt nanotube samples were heated to $900{ }^{\circ} \mathrm{C}$, the resulting $\mathrm{FePt}$ nanoparticles have coercivities as high as $38 \mathrm{kOe}$ at $5 \mathrm{~K}$ and $29.1 \mathrm{kOe}$ at $300 \mathrm{~K}$.

In Fig. 5(b) we see room temperature hysteresis loops for $\mathrm{Fe}_{3} \mathrm{O}_{4}$ tubes that have been reduced at $250{ }^{\circ} \mathrm{C}$ for 2.5 and $4 \mathrm{~h}$. In each case, the coercivity is considerably lower than that of the FePt system. After being reduced for only $2.5 \mathrm{~h}$, XRD indicates that the tubes consist entirely of $\mathrm{Fe}_{3} \mathrm{O}_{4}$. The hysteresis loops show a remanence of about $50 \%$, a coercivity of $600 \mathrm{Oe}$, and a shape that is reminiscent of magnetizing along an easy axis. This is to be expected from shapeanisotropy arguments. After reducing for a longer time, XRD shows a composition change and this is observed in the magnetic behavior. The hysteresis loops on the tubes containing an $\alpha$-Fe phase have a lower remanence, a lower coercivity, and have a higher saturating field. This may be connected with the presence of two exchange-coupled magnetic phases with different anisotropies and morphologies. A detailed discussion of the magnetic properties of these systems appears elsewhere. ${ }^{14}$

\section{DISCUSSION AND CONCLUSIONS}

These magnetic nanotubes may have interesting applications. For example, nanoscale magnetic field sources are prerequisites to making nanoelectromechanical system devices feasible. ${ }^{15}$ Magnetic nanotubes could be used as Halbach cylinders to create homogeneous cavity fields which are, in general, larger than the saturation magnetization of the material. ${ }^{16}$ Also, the low-energy curling flux closure in these tubes could be used as nonvolatile memory units if the tubes are created in templates with an ordered pore structure. ${ }^{17}$ In addition, magnetic nanotubes also may have possible applications in high-density magnetic recording, ${ }^{3}$ biomagnetic sensors, nanomedicine, and catalysts. ${ }^{18,19}$

In conclusion, hydrogen reduction has been used to produce ferromagnetic $\mathrm{FePt}$ and $\mathrm{Fe}_{3} \mathrm{O}_{4}$ nanotubes. The structure and magnetism of these tubes has been investigated by SEM, TEM, XRD, and SQUID magnetometry. We have found that nanotubes of FePt with an $L 1_{0}$ crystal structure are synthesized by reducing an appropriate $\mathrm{Fe}$ chloride and $\mathrm{Pt}$ chloride mixture inside the pores of alumina templates. $\mathrm{Fe}_{3} \mathrm{O}_{4}$ nanotubes are formed in these same templates by thermal pyrolysis of iron nitrate before hydrogen reduction. An analysis of the microstructure reveals both that the tubes are polycrystalline and that composition of the tubes is strongly dependent upon the reducing time and temperature. Magnetic analysis confirms the compositional details as well as the ordering of the crystal structure in the FePt tubes.

\section{ACKNOWLEDGMENTS}

This work is supported by DOE, NSF-MRSEC, AFOSR, CMRA, and NRI. We would like to thank Xingzhong Li, Jian Zhou, Kit Lee, and Joe Zhou for assistance and helpful discussions.

${ }^{1}$ S. Sun, C. B. Murray, D. Weller, L. Folks, and A. Moser, Science 287, 1989 (2000)

${ }^{2}$ R. Skomski, J. Phys.: Condens. Matter 15, R841 (2003).

${ }^{3}$ S. Khizroev, M. H. Kryder, D. Litvinov, and D. A. Thompson, Appl. Phys. Lett. 81, 2256 (2002).

${ }^{4}$ M. N. Wu, Y. C. Zhu, H. G. Zheng, and Y. T. Qian, Inorg. Chem. Comm. 5, 971 (2002)

${ }^{5}$ G. Tourillon, L. Pontonnier, J. P. Levy, and V. Langlais, Electrochem. Solid-State Lett. 3, 20 (2000).

${ }^{6}$ J. C. Bao, C. Y. Tie, Z. Xu, Q. F. Zhou, D. Shen, and Q. Ma, Adv. Mater. (Weinheim, Ger.) 13, 1631 (2001).

${ }^{7}$ C. J. Brumlik and C. R. Martin, J. Am. Chem. Soc. 113, 3174 (1991).

${ }^{8}$ D. J. Sellmyer, M. Zheng, and R. Skomski, J. Phys.: Condens. Matter 13, R433 (2001), references therein.

${ }^{9}$ Y. H. Huang, H. Okumura, G. C. Hadjipanayis, and D. Weller, J. Appl. Phys. 91, 6869 (2002).

${ }^{10}$ Y. Sui, L. Yue, R. Skomski, X. Z. Li, J. Zhou, and D. J. Sellmyer, J. Appl. Phys. 93, 7571 (2003).

${ }^{11}$ Y. C. Sui, B. Z. Cui, L. Martinez, R. Perez, and D. J. Sellmyer, Thin Solid Films 406, 64 (2002).

${ }^{12} \mathrm{~S}$. A. Chambers, T. Droubay, D. R. Jennison, and T. R. Mattsson, Science 297, 827 (2002).

${ }^{13}$ P. P. Mardilovich, A. N. Govyadinov, N. I. Mukhurov, A. M. Rzhevskii, and R. Paterson, J. Membr. Sci. 98, 131 (1995).

${ }^{14}$ Y. C. Sui, R. Skomski, K. D. Sorge, and D. J. Sellmyer, Appl. Phys. Lett. 84, 1525 (2004).

${ }^{15}$ M. Zahn, J. Nanopart. Res. 3, 73 (2001).

${ }^{16}$ R. Skomski and J. M. D. Coey, Permanent Magnetism (Institute of Physics, Bristol 1999).

${ }^{17}$ R. P. Cowburn, D. K. Koltsov, A. O. Adeyeye, M. E. Welland, and D. M. Tricher, Phys. Rev. Lett. 83, 1042 (1999).

${ }^{18}$ A. S. Goldstein, M. H. Gelb, and P. J. Yager, J. Controlled Release 70, 125 (2001).

${ }^{19}$ C. A. Haberzettl, Nanotechnology 13, R9 (2002). 